PESQUISA

\title{
PRINCIPAIS CAUSAS DE CONDENAÇÃO DE CARCAÇAS DE FRANGOS DE CORTE EM ABATEDOUROS SOB INSPEÇÃO FEDERAL NO ESTADO DO PARANÁ, BRASIL
}

\section{MAIN CAUSES OF CHICKEN CARCASSES CONDEMNATIONS IN SLAUGHTERS UNDER FEDERAL INSPECTION IN THE STATE OF PARANÁ, BRAZIL}

Catarina Demarchi de Oliveira ${ }^{1}$

Departamento de Produção Animal e Medicina Veterinária Preventiva. Faculdade de Medicina Veterinária e Zootecnia, UNESP, Campus de Botucatu, Botucatu, São Paulo, Brasil. E-mail: catarina.demarchi0@gmail.com

ORCID: https://orcid.org/0000-0003-3132-5492

Aryele Nunes da Cruz Encide Sampaio²

Departamento de Produção Animal e Medicina Veterinária Preventiva. Faculdade de Medicina Veterinária e Zootecnia, UNESP, Campus de Botucatu, Botucatu, São Paulo,

Brasil. E-mail: aryele.sampaio@unesp.br

ORCID: https://orcid.org/0000-0003-3648-2382

\section{Juliano Gonçalves Pereira ${ }^{3}$}

Departamento de Produção Animal e Medicina Veterinária Preventiva. Faculdade de Medicina Veterinária e Zootecnia, UNESP, Campus de Botucatu, Botucatu, São Paulo,

Brasil. E-mail: juliano.pereira@unesp.br

ORCID: https://orcid.org/0000-0002-8713-7506

'Obtenção dos dados, Tabulação de dados, Escrita - primeira redação, Escrita - Revisão e Edição.

2Escrita - primeira redação, Escrita - Revisão e Edição.

${ }^{3}$ Escrita - primeira redação, Escrita - Revisão e Edição, Supervisão. 
RESUMO: Objetivou-se, neste estudo, analisar as principais causas de condenação total de carcaças de frangos de corte em frigoríficos sob o Serviço de Inspeção Federal no Paraná, no período de janeiro de 2017 a dezembro de 2018. Foram analisados os registros de abate, obtidos através do Sistema de Informações Gerenciais do Serviço de Inspeção Federal, e os relatórios de condenações por meio do Sistema Eletrônico do Serviço de Informação ao Cidadão. As principais causas de condenação, registradas no período em estudo foram aspecto repugnante $(28,7 \%)$, contaminação $(19,3 \%)$, síndrome ascítica (11\%) e escaldagem excessiva (9,6\%). 65,5\% das condenações das carcaças foram de origem não patológica, identificadas como tecnopatias.

Palavras-chave: Carcaça de frango; Condenação; Inspeção.

ABSTRACT: The aim of this study was to analyze the main causes of total condemnation of broiler carcasses in slaughterhouses under the Federal Inspection Service in Paraná, from January 2017 to December 2018. The slaughter records obtained through Management Information System of the Federal Inspection Service, and reports of convictions through the Electronic System of the Citizen Information Service. The main causes of condemnation recorded in the study period were disgusting aspects (28.7\%), contamination (19.3\%), ascitic syndrome $(11 \%)$ and excessive scalding $(9.6 \%) .65,5 \%$ of carcass convictions were of non-pathological origin and were identified as technopathies.

Keywords: Chicken; Condemnation; Inspection.

\section{INTRODUÇÃO}

O estado do Paraná é o maior produtor e exportador de carne de frango do Brasil. No ano de 2018, foram produzidos 4,31 milhões de toneladas, correspondente a $31,4 \%$ da produção nacional (IBGE, 2019; SEAB, 2019).

Visando a garantia da qualidade higiênico-sanitária dos produtos de origem animal destinados ao consumo humano e animal, bem como a comercialização interna e externa, o Serviço de Inspeção Federal (SIF) realiza atividades de inspeção e fiscalização do processo produtivo. Essas atividades são privativas ao Médico Veterinário, o qual segundo o Regulamento da Inspeção Industrial e Sanitária de Produtos de Origem Animal (RIISPOA), julga as ocorrências durante o procedimento de abate. A Inspeção de Aves também se baseia na Portaria nํ210, de 10 de novembro de 1998 (BRASIL, 1998; BRASIL, 2017).

Embora o Brasil ocupe posição de destaque na avicultura mundial, problemas com a qualidade das carcaças e relevante número de condenações levam a perdas econômicas significativas para 0 setor (EBLING \& BASURCO, 2016). As condenações de carcaças nos abatedouros frigoríficos de aves sob SIF, decorrem de tecnopatias e achados sugestivos de doenças infectocontagiosas ou parasitárias, incluindo zoonoses. Essas lesões são identificadas nas linhas de inspeção e determinam o destino das carcaças e órgãos, garantindo a inocuidade do alimento (BRASIL, 2017).

O objetivo do presente estudo foi descrever as principais causas de condenação total de carcaças de frangos 
de corte em abatedouros frigoríficos sob o Serviço de Inspeção Federal no estado do Paraná, no período de janeiro de 2017 a dezembro de 2018.

\section{MATERIAL E MÉTODOS}

Realizou-se um levantamento de dados a partir dos relatórios gerados nos estabelecimentos sob Serviço de Inspeção Federal no Paraná, disponíveis no Sistema de Informações Gerenciais do Serviço de Inspeção Federal (SIGSIF). O SIGSIF, sistema informatizado, foi criado em 2003 e armazena os relatórios das lesões identificadas pelo SIF durante 0 procedimento de abate (SIGSIF, 2020).

Analisou-se relatórios de abates por ano e UF relativos ao quantitativo de abate estadual por ano e espécie, bem como o número de aves abatidas no período de janeiro de 2017 a dezembro de 2018, no estado do Paraná. Os relatórios das categorias de aves foram analisados separadamente e calculou-se a frequência de frangos dentre todas as aves abatidas no período.

Foram solicitados ao MAPA, através do Sistema Eletrônico do Serviço de Informação ao Cidadão - e-SIC (e-SIC, 2019), os relatórios de destino de matériasprimas e produtos por UF onde estavam registradas as condenações de aves separadas por diagnóstico e respectivo destino.
As causas de condenações relatadas foram divididas em não patológicas (abscesso, aspecto repugnante, sangria inadequada, contaminação, contusão, escaldagem excessiva e evisceração retardada) e patológicas (aerossaculite, artrite, caquexia, celulite, colibacilose, dermatose, edema, miopatia, neoplasia, salpingite, septicemia, síndrome ascítica e síndrome hemorrágica).

Uma seleção preliminar foi realizada a partir dos dados de carcaças que sofreram condenação total calculando-se a frequência relativa e a taxa de condenações em relação ao total de aves abatidas no período estudado. A análise descritiva simples foi elaborada utilizandose o programa Microsoft Excel.

\section{RESULTADOS E DISCUSSÃO}

No período de janeiro de 2017 a dezembro de 2018, foram abatidas 3.614.168.073 aves em abatedouros frigoríficos sob o Serviço de Inspeção Federal no Paraná. Segundo relatórios de abate das categorias de aves, esse número corresponde a 95,98 \% de frangos, $3,59 \%$ de galinhas, $0,36 \%$ de perus e 0,06 $\%$ de galos. A quantidade abatida de galinhas de postura e galinhas d'angola foi considerada irrelevante, sendo desconsiderada neste estudo.

No período em estudo, obteve-se um total de 16.374 .560 carcaças de aves destinadas a condenação total post 
mortem, com frequência de $0,45 \%$ de condenações em relação ao total abatido no período. Cerca de 65,5 \% das condenações ocorreram em razões não patológicas e $34,5 \%$ por patologias (Tabela 1).

As condenações patológicas podem estar relacionadas a doenças que refletem falhas sanitárias ou manejo inadequado, enquanto as não patológicas, também denominadas de tecnopatias, são atribuídas a falhas tecnológicas no manejo pré-abate e no processo de obtenção de carcaças e vísceras (MASCHIO \& RASZL, 2012).

A principal causa de condenação total de carcaças de frangos foi o aspecto repugnante, o qual representou $28,7 \%$ do total e frequência de $0,13 \%$. Resultados semelhantes foram descritos por Paschoal et al. (2012) que identificaram o aspecto repugnante como a principal causa de condenação (47,33%). Entretanto, Quadros et al. (2019) descrevem esta como sendo a segunda maior causa de condenações de carcaças em Santa Catarina (18\%).

Os principais achados de aspecto repugnante são alterações na coloração e musculatura, conhecidas como carnes DFD (dark, firm and dry) e PSE (pale, soft and exsudative), que resultam do estresse pré-abate causado, principalmente, pelo manejo inadequado dos animais (SHIRAISHI et al., 2013). Diante disso, as carcaças com aspecto repugnante, congestos, com coloração anormal ou com degenerações, além daquelas em processo putrefativo que exalem odores anormais, devem ser condenadas (BRASIL, 2017).

Tabela 1 - Principais causas de condenação total em carcaças de frangos de corte em frigoríficos sob Serviço de Inspeção Federal no estado do Paraná nos anos de 2017 e 2018.

\begin{tabular}{cccc}
\hline Causas & Condenação (N) & Frequência (\%) & Taxa de condenações (\%) \\
\hline Aspecto repugnante & 4.706 .058 & 28,7 & 0,13 \\
Contaminação & 3.155 .475 & 19,3 & 0,09 \\
Síndrome ascítica & 1.801 .565 & 11,0 & 0,05 \\
Escaldagem excessiva & 1.574 .285 & 9,6 & 0,04 \\
Colibacilose & 1.217 .764 & 7,4 & 0,03 \\
Caquexia & 891.215 & 5,4 & 0,02 \\
Sangria inadequada & 567.796 & 3,5 & 0,02 \\
Celulite & 502.177 & 3,1 & 0,01 \\
Dermatose & 361.995 & 2,2 & 0,01 \\
Evisceração retardada & 313.294 & 1,9 & 0,01
\end{tabular}


A condenação por contaminação representou 19,3 \% das carcaças rejeitadas e uma frequência de 0,09 \% no abate. Almeida et al. (2018) encontraram resultados semelhantes, os quais descreveram a contaminação como a segunda maior causa de condenação de carcaças de frango no norte do país $(14,41$ \%). Já Oliveira et al. (2016) relatou que a contaminação representou $30 \%$ das causas de condenação em seu estudo.

A contaminação pode ocorrer por uma falha tecnológica, associada ao rompimento do trato intestinal ou vesícula biliar durante o abate de animais com repleção do trato gastrointestinal ou devido a falhas nos equipamentos de evisceração durante 0 abate de lotes desuniformes (MASCHIO \& RASZL, 2012). Aves devem cumprir o período mínimo de 6 a 8 horas de jejum pré-abate, com o objetivo de evitar possíveis contaminações do trato gastrointestinal durante o processamento (BRASIL, 1998), sendo as carcaças condenadas quando há impossibilidade de completa remoção da parte contaminada (BRASIL, 2017).

Para que o intestino seja esvaziado e evitando a contaminação, Mendes (2001) afirma que a ração e a água não devem ser retiradas ao mesmo tempo, pois a água solubiliza o alimento no papo e favorece a passagem do mesmo para o intestino.
Além disso, a ausência de alimento no intestino provoca uma mudança no $\mathrm{pH}$ que pode favorecer a multiplicação de patógenos no trato gastrointestinal. Um estudo realizado por Ramirez et al. (1997) concluiu que o jejum aumenta a incidência de Salmonella no papo de frangos e indica que este pode ser um importante ponto crítico de controle para reduzir a contaminação de carcaças. Mendes (2001) ainda destaca que a ruptura de papo ocorre com maior frequência quando comparada a de ceco durante a evisceração mecânica.

A principal causa patológica, representada pela terceira maior causa de condenação neste estudo, foi a síndrome ascítica, frequente em $0,05 \%$ do total de abates e registrada em $11 \%$ das aves condenadas. Quadros et al. (2019) relatam a mesma frequência (11 \%) em abatedouros no estado de Santa Catarina, constituindo a quarta maior causa de condenação total no estudo. Resultado semelhante $(96 \%)$ foi descrito por Jacobsen \& Flôres (2008). Maschio e Raszl (2012) relatam a ascite como a principal causa de condenação total de carcaças de frangos $(26,76 \%)$ na região Sul do país.

O quadro ascítico é caracterizado pelo acúmulo de líquido na cavidade abdominal e está relacionado ao sistema cardiorrespiratório, podendo ser 
desencadeado por qualquer fator que predispõe à hipóxia. A deficiência leva ao aumento do débito cardíaco, hipertensão pulmonar, resultando na hipertrofia cardíaca e refluxo sanguíneo para o organismo e perda de líquido vascular (MACARI et al., 1994; COELLO, 1991; GONZALES \& MACARI, 2000). Gonzales e Macari (2000), ressaltam que a ascite causa grandes perdas em lotes de frangos que são submetidos a baixas temperaturas, altitude elevada, alta taxa de crescimento, ventilação deficiente, patologias pulmonares e uso de rações de alta energia na alimentação.

As lesões por escaldagem excessiva foram registradas em $9,6 \%$ das condenações, perfazendo a quarta maior causa de condenação e com frequência de $0,04 \%$ no abate. Resultado semelhante ( 7 \%) foi descrito por Quadros et al. (2019) em Santa Catarina. Entretanto, Silva (2016) relatou que apenas 0,0037 \% de carcaças foram condenadas por escaldagem excessiva em um município do estado do Mato Grosso do Sul. Essa tecnopatia ocorre principalmente nos casos de parada nas linhas de abate, temperatura inadequada dos tanques de escalda, tempo exacerbado e má regulagem de equipamentos, causando queimaduras e endurecendo a carne (BRASIL, 1998; GOMIDE et al., 2006; SILVA \& PINTO, 2009). Carcaças com lesões extensas devem ser condenadas (BRASIL, 2017).
As condenações por colibacilose representaram 7,4 \%, resultado semelhante ao descrito por Ebling \& Basurco (2016) de 7,65 \% em estudo realizado nos principais estados produtores de frangos de corte no Brasil. Entretanto, foi inferior aos 19,8 \% encontrados em abatedouros frigoríficos no Rio Grande do Sul, os quais registraram a colibacilose como principal causa de condenação (SESTERHENN et al., 2011). Escherichia coli patogênica para aves (APEC) é o principal agente etiológico da enfermidade que acomete principalmente $o$ trato respiratório e caracteriza-se por traqueíte, aerossaculite, pneumonia, polisserosite e pericardite podendo evoluir para quadro sistêmico (BARNES et al., 2008).

A caquexia foi descrita em $5,4 \%$ das carcaças condenadas neste estudo. Ebling \& Basurco (2016) apontam que $16 \%$ das condenações estão relacionadas a caquexia, enquanto Santana et al. (2018) registraram $0,09 \%$, resultados inferiores aos $26,6 \%$ encontrados por Ferreira et al. (2012), no estado do Rio Grande do Sul. A caquexia é caracterizada pela perda de massa muscular e tecido adiposo com proeminência do esterno. Os animais subnutridos devem ser considerados magros e a caquexia é atribuída aos que possuem histórico de enfermidades infecciosas ou neoplásicas. Essas condições podem estar relacionadas com a diminuição do apetite ou falha na absorção, 
podendo ser vistas no escore corporal do animal (GREGORY \& ROBINS, 1998; HOWARD \& SENIOR, 1999). Todas as carcaças caquéticas devem ser condenadas (BRASIL, 2017).

As carcaças com aspecto sanguinolento totalizaram 3,5\% das aves condenadas. O resultado foi inferior ao encontrado por Paschoal et al. (2012) de 23,09 \% e Maschio \& Raszl (2012) de $14,39 \%$, os quais registraram a sangria inadequada como uma das maiores causas de condenação total, principalmente devido ao fato da sangria ter sido realizada manualmente. Segundo os autores, tais condenações poderiam ser evitadas com o treinamento regular dos funcionários e a manutenção preventiva dos equipamentos. Carnes com aspecto sanguinolento podem decorrer de falhas na regulagem dos equipamentos de sangria ou falha na incisão manual (MASCHIO \& RASZL, 2012). Além de influenciar a qualidade microbiológica da carcaça (TAVERNARI et. al., 2012), o tempo de sangria prolongado pode comprometer a depenagem pois as penas são aprisionadas pelos folículos após o rigor mortis (ROÇA, 2000). A sangria de aves deve ocorrer em até doze segundos após a insensibilização, com uma duração de no mínimo três minutos para assegurar o escoamento máximo de sangue (BRASIL, 1998). Segundo o grau de comprometimento e a julgamento do SIF, as carcaças podem ser condenadas ou tratadas pelo calor (BRASIL, 2017).

A celulite foi observada em $3,1 \%$ das carcaças. Resultados superiores foram descritos por Ferreira et al. (2012) de 8,3\% e Santana et al. (2008) de 51,20 \% que registraram a celulite como uma das maiores causas de condenações em abatedouros no Rio Grande do Sul e Goiás, respectivamente. A celulite é uma inflamação purulenta aguda e difusa do tecido subcutâneo, caracterizada por espessamento da derme e formação de placas fibrino-caseosas, ocorrendo alterações na coloração da pele que variam do amarelo ao marrom. A Escherichia coli é o principal agente etiológico da celulite em aves (MESSIER et al., 1993; NORTON, 1997; ONDERKA et al., 1997; FALLAVENA, 2000; FERREIRA et al., 2012). Segundo Schrader et al. (2004), a alta concentração de E. coli nos galpões, aumenta 0 risco do desenvolvimento de celulite aviária. A alta densidade de animais e baixa qualidade da cama facilitam a ocorrência de lesões cutâneas permitindo a penetração da bactéria e desenvolvimento da enfermidade (NORTON, 1997; PEIGHAMBARI et al., 1995). As carcaças com lesões na pele ou carne devem ser rejeitadas quando a condição geral for comprometida (BRASIL, 1998).

Lesões classificadas como dermatose representaram 2,2 \% das condenações. Resultado semelhante ao 
obtido por Almeida et al. (2018). Entretanto diferem significativamente dos 13,27 \% descritos por Ebling \& Basurco (2016) e 0,74 \% de Oliveira et al. (2016). O exame histológico é uma importante ferramenta para classificar as lesões por dermatopatias (FALLAVENA et al., 2001)

$$
\text { A evisceração retardada }
$$
representou $1,9 \%$ das causas de condenação das carcaças. Resultado análogo à média obtida em um estudo realizado nos principais estados produtores de frangos de corte no Brasil, onde Ebling \& Basurco (2016) encontraram $0,72 \%$ em Santa Catarina, 2,78 \% no Paraná, 3,65 \% em São Paulo e 0,49 \% em Rio Grande do Sul. A evisceração retardada ocorre quando há interrupção do processo de abate a partir de trinta minutos após a sangria (BRASIL, 1998; PEREIRA, 2009). As carcaças são rejeitadas nos casos em que o aspecto organoléptico está alterado e seu destino varia de acordo com critérios de condenação estabelecidos pelo veterinário responsável pelo serviço de inspeção (SOUZA et al., 2016).

\section{CONSIDERAÇÕES FINAIS}

As principais causas de condenação total em carcaças de frangos de corte registradas em frigoríficos sob serviço de Inspeção Federal no Paraná foram aspecto repugnante, contaminação, síndrome ascítica e escaldagem excessiva. A maioria das condenações estão relacionadas a tecnopatias que podem ser evitadas pelo treinamento regular dos funcionários e a manutenção preventiva dos equipamentos, reduzindo a condenação de carcaças nos abatedouros.

Os serviços de inspeção que atuam nos estabelecimentos cárneos são essenciais para garantir e assegurar a inocuidade dos produtos destinados ao consumo. O controle periódico das condenações nos abatedouros é uma importante ferramenta para a melhoria das condições de manejo e abate de aves, uma vez que podem minimizar as perdas econômicas causadas pelas condenações de carcaças de frangos.

\section{REFERÊNCIAS BIBLIOGRÁFICAS}

ALMEIDA, T. J. DE OLIVERA. et al. Causas de condenação de carcaças de Gallus gallus domesticus em abatedouros frigoríficos sob Inspeção Federal no Nordeste do Brasil. Medicina Veterinária UFRPE, v.11, n.4, 2018.

BARNES H. J.; NOLAN L. K.; VAILLANCOURT J. P. Colibacillosis. In: SAYF, Y. M. Diseases of Poultry, $12^{\mathrm{a}}$ ed. Ames: Blackwell, cap. 18, p.691-737, 2008.

COELLO, A. et al. Investigaciones sobre el síndrome ascético em polos de engorda. Ciência Veterinária, n. 5, p. 13-48, 1991.

DEEB, N.; CAHANER, A. Genotype-byenvironment interaction with broiler genotypes differing in growth rate: The effects of high ambient temperature on dwarf versus normal broilers. Poultry Science, Ithaca, v.80, p.541-548, 2001.

EBLING, P. D.; BASURCO V. Análise das perdas econômicas oriundas da 
condenação de carcaças nos principais estados brasileiros produtores de frangos de corte. Revista Ciências Agroveterinárias e Alimentos, n. 21, 2016.

FALLAVENA, L. et al. Diagnosis of skin lesions in condemned or downgraded broiler carcasses - A microscopic and macroscopic study. Avian pathology: Journal of the W.V.P.A, v. 29, p. 557-62, 2001.

FERREIRA A.J.P.; KNÖBE T. 2008. Enfermidades bacterianas, p.435-563. In: Berchieri Jr A. \& Macari M. (Eds), Doenças das Aves, FACTA, Campinas, p.435-563, 2008.

FERREIRA, T. Z.; SESTERHENN, R.; KINDLEIN, L. Perdas econômicas das principais causas de condenações de carcaças de frangos de corte em matadouros-frigoríficos sob inspeção federal no Rio Grande do Sul, Brasil. Acta Scientiae Veterinariae, v. 40, n. 1, p. 1-6, 2012.

FREITAS, L. S. Causas de condenações post-mortem em carcaças de frangos. Dissertação (especialização), Universidade Federal do Rio Grande do Sul. Curso de Especialização em Produção, Tecnologia e Higiene de Alimentos de Origem Anima. Porto Alegre - RS, 2015.

GOMIDE, L. A.; RAMOS E.; FONTES P. R. Tecnologia de abate e tipificação de carcaças. Viçosa: UFV, p.370, 2006.

GONZALES, E.; MACARI M. Enfermidades metabólicas em frangos de corte. In: BERCHIERI Jr. A.; MACARI, M. Doenças das Aves, Campinas: FACTA. Cap. 9, p.451-464, 2000.

GOSCINSCKI, F. Análise dos índices de condenação de carcaças de frango em abatedouro da região norte paranaense. Higiene Alimentar, v. 30, n 260/261, 2016.

GREGORY, N. G.; ROBINS, J. K. A body condition scoring system for layer hens.
New Zealand J. Agric. Res, v. 41, n. 4, p. 555-559, 1998.

HOWARD, J.; SENIOR, D. F. Cachexia and nutritional issues in animals with cancer. Journal of the American Veterinary Medical Association, v. 214, n. 5, p. 632637, 1999.

Instituto Brasileiro de Geografia e Estatística. Estatística de produção pecuária out. - dez. 2019. Disponível em: <https://biblioteca.ibge.gov.br/visualizacao /periodicos/2380/epp_2018_4tri.pdf>.

Acesso em: 10 maio 2020.

JACOBSEN, G.; FLÔRES, M.L. Condenações por síndrome ascítica em frangos abatidos sob inspeção federal entre 2002 e 2006 no Estado do Rio Grande do Sul, Brasil. Ciência Rural, v.38, n.7, p.1966-1971, 2008.

KOTLER, D. P. Cachexia. Ann Intern Med, v. 133, n. 8, p.622-634, 2000.

MACARI, M. FURLAN, R.L., GONZALES, $E$. Fisiologia aviária aplicada a frangos de corte, FUNEP/UNESP, Jaboticabal, São Paulo, p.296, 1994.

MASCHIO, M.M.; RASZL, S. M. Impacto financeiro das condenações post-mortem parciais e totais em uma empresa de abate de frango. Revista E-tech, v. 1, n. 1, p. 2638, 2012.

MENDES, A. A. Jejum Pré-abate em Frangos de Corte. Revista Brasileira Ciência Avícola, Campinas, v. 3, n. 3, p. 199-209, 2001.

MESSIER, S. et al. Focal dermatitis and cellulitis in broiler chickens: bacteriological and pathological findings. Avian Diseases, v. 37, n. 3, p. 839-844, jul./set. 1993.

NORTON, R. A. Avian cellulitis. World's Poultry Science Journal, v. 53. n. 4, p. 337-349, dez. 1997.

ONDERKA, D. K. et al. Escherichia coli Associated Cellulitis in Broilers: Correlation with Systemic Infection and Microscopic 
Visceral Lesions, and Evaluation for Skin Trimming. Avian Diseases, v. 41, n. 4, p. 935-940, out./dez. 1997.

PASCHOAL, E. C.; OTUTUMI, L. K.; SILVEIRA, A. P. Principais causas de condenações no abate de frangos de corte de um abatedouro localizado na região noroeste do Paraná, Brasil. Arq. Ciênc. Vet. Zool. UNIPAR, v. 15, n. 2, p. 93-97, jul./dez. 2012.

PEIGHAMBARI, S. M.; JULIAN, R. J.; VAILLANCOURT, J. P.; GYLES, C. L. Escherichia coli Cellulitis: Experimental Infections in Broiler Chickens. Avian Diseases, v. 39, n. 1, p. 125-134, jan./mar. 1995.

PEREIRA, S. L. S. Condenação no Abate de Frangos de Corte. Monografia (especialização) Higiene e Inspeção de Produtos de Origem Animal e Vigilância Sanitária em Alimentos - Universidade Castelo Branco. Campinas, p. 38, 2009.

QUADROS, A. T. et al. Principais causas de condenação total de frangos em abatedouros de Santa Catarina. 2019. Disponível em: <https://eventos.uceff.edu.br/eventosfai_d ados/artigos/agrotec2019/1140.pdf>. Acesso: 21 maio 2020.

RAMIREZ G. A. et al. Effect of Feed Withdrawal on the Incidence of Salmonella in the Crops and Ceca of Market Age Broiler Chickens. Poultry Science, v. 76, n. 4, p. 654-656, Abril 1997.

ROÇA, R. O. Abate de aves. Disponível em:

<https://www.fca.unesp.br/Home/Instituica o/Departamentos/Gestaoetecnologia/Tese s/Roca104.pdf>. Acesso: 25 Abril 2020.

SANTANA, A. P. et al. Causes of condemnation of carcasses from poultry in slaughterhouses located in State of Goiás, Brazil. Ciência Rural, v. 38, n. 9, p. 25872592, dez. 2008.

SCHRADER, J. S.; SINGER, R. S.; ATWILL, E. R. A Prospective Study of
Management and Litter Variables Associated with Cellulitis in California Broiler Flocks. Avian Diseases, v. 48, n. 3, p. 522-530, out. 2004

Secretaria de Estado da Agricultura e do Abastecimento Departamento De Economia Rural. Números da pecuária paranaense. 2019. Disponível em: <http://www.agricultura.pr.gov.br/system/fil es/publico/Conjuntura/nppr.pdf>. Acesso:

SESTERHENN $R$. et al. Impacto econômico de condenações post mortem de aves sob inspeção estadual no estado do Rio Grande do Sul. In: Anais Congresso Brasileiro de Medicina Veterinária, 38., 2011, Gramado, RS. Disponível em: <https://www.yumpu.com/pt/document/rea d/12675973/impacto-economico-decondenacoes-post-sovergs>. Acesso: 23 Maio 2020.

SHIRAISHI, V. T. I.; LEITE, P. A. G.; NASCIMENTO, K. R. Condenações por aspecto repugnante em frangos abatidos sob inspeção Estadual, no município de São Gonçalo dos Campos - Bahia, Brasil. Veterinária e Zootecnia, v. 20, n. 2, p. 318-25, 2013.

SILVA, V. A. M.; PINTO, A. T. Levantamento das condenações de abate de frangos e determinação das causas mais prevalentes em um frigorífico em Santa Catarina. In: Anais Congresso Brasileiro de Avicultura, 21., 2009, Porto Alegre, RS. Porto Alegre: APINCO, p.212213, 2009. Disponível em: <https://www.avisite.com.br/cet/img/20090 812_lamas7.pdf>. Acesso: 22 maio 2020.

Sistema Eletrônico do Serviço de Informação ao Cidadão. 2019. Disponível em:

<https://esic.cgu.gov.br/sistema/principal.a spx>. Acesso: 10 maio 2020.

Sistema de Informações Gerais do Serviço de Inspeção Federal. 2019. Disponível em:<

http://sigsif.agricultura.gov.br/primeira_pag 
na/extranet/SIGSIF.html>. Acesso: 10 maio 2020.

SOUZA, I. J. G. S. et al. Condenações não patológicas de carcaças de frangos em um matadouro-frigorífico sob inspeção federal no estado do Piauí. Revista Brasileira de Higiene e Sanidade Animal, v. 10, n. 1, p. 68-77, jan./mar. 2016.

TAVERNARI, F. C.; ALBINO, L. F. T.; ARAÚJO, W. A. G. Manejo pré-abate de frangos de corte. Revista CFMV, Brasília, n. 56, p. 62-68, 2012. 